\title{
An Integrative Review: Translating the Experiences of Youth Psychiatry Patients to Improve Primary Healthcare Outcomes
}

\author{
Jane McLaughlin $^{1}$ and Kathryn Weaver ${ }^{2}$ \\ ${ }^{1}$ Nurse Practitioner, Primary Care Practice, Canada \\ ${ }^{2}$ Professor, Faculty of Nursing, University of New Brunswick, Canada \\ ${ }^{1}$ jane.mclaughlin@unb.ca, ${ }^{2}$ kweaver@unb.ca
}

\begin{abstract}
This integrative review aims to sensitize primary care nurse practitioners and physicians to the traumatic care experiences of youth psychiatry patients and provide recommendations for patient care using a trauma-informed approach. Two electronic, combined CINAHL and PsychInfo searches and a manual search of the references of included articles for the years 2000-2019 were completed. Using Whittemore and Knafl's integrative review method, data from 22 articles were synthesized. Traumatic care, although not widely recognized by primary care providers, was shown to result in a negative effect on admission policies, procedures, and safety measures enforced in youth psychiatry units. Traumatic care themes included coercive care, seclusion, loss of control, safety, and post-traumatic stress disorder after discharge. Trauma-informed care training was found to improve patient-provider relationships and reduce the adverse health outcomes associated with trauma exposure. Universal trauma screening is recommended in all care areas to identify traumatic experiences, enhance patient-provider relationships, and reduce adverse health outcomes associated with non-addressed traumas.
\end{abstract}

Keywords: Integrative review, Nurse practitioner, Post-traumatic stress disorder, Psychiatry, Swanson's caring theory, Traumatic care, Trauma-informed care, Youth

\section{Introduction}

The term traumatic care is used to describe patient-perceived trauma that stems from inpatient experiences. The trauma is without intent and is consequential to admission policies, procedures, and safety measures implemented by healthcare providers who work in psychiatry units [1][2][3]. While the term traumatic care is primarily used within psychiatry, patient accounts of traumatic experiences related to their care can occur in a multitude of settings including emergency, labor and delivery, and oncology units [4]. According to Green et al. [5], traumatic care predicts the development or worsening of mental disorders and negative health outcomes for patients. Despite the correlation between exposure to traumatic care and adverse health outcomes, Primary Care Providers (PCPs), including primary care nurse practitioners and physicians, continue to report an incomplete understanding of the effects of traumatic care [5]. Traumatic care experiences that are not identified by PCPs after a patient is discharged from the psychiatry unit increase the probability for the patient to

Article History:

Received (November 16, 2019), Review Result (December 25, 2019), Accepted (January 29, 2020) 
experience long-term adverse health outcomes, poor coping, and the development of posttraumatic stress disorder [6].

Adult mental health patients admitted to psychiatry units generally report low satisfaction rates. Specifically, the Mood Disorders Society of Canada [7] found 63\% of the 2245 patients who completed satisfaction surveys in June 2015 were dissatisfied with the mental health treatment provided by healthcare professionals. Wait times, lack of empathy/respect, "rushed" consultations, and being cared for by PCPs having a "lack of knowledge/ training/ understanding" were the primary sources of dissatisfaction. Patients whose PCPs use a trauma-informed approach reported higher satisfaction rates when they sensed a connection with their care providers and felt safe, secure, and accepted [2]. It is important to determine a patient's satisfaction regarding psychiatric care as this conveys to patients that their opinion and participation in their care are valued and can assist the provider to identify unmet needs [8]. A Trauma-informed Care (TIC) approach demonstrates providers' deep understanding of the effects, human responses to, and medical and physical symptoms of traumatic stress [9]. TIC is a strengths-based focus on developing an emotionally safe atmosphere that helps rebuild control by involving patients in service design and evaluation [10].

We emphasize youth psychiatry patients because youth are among the most vulnerable populations in the healthcare world due to their dependency on others and we know that most mental illnesses of adult life begin in adolescence. The Canadian Institute for Health Information [14] reported that a total of 42,623 Canadian youth, aged 5-24, required an Emergency Department visit for a mental health-related problem in 2006-2007. This number rose to 74,757 in 2016-2017, a greater than $170 \%$ increase. Similarly, Canadian youth, in the same age bracket and year comparison, who required hospitalization for mental health disorders increased $155 \%$ from 25,055 to 38,999 [14]. Psychiatric hospitalizations for youth are for the majority due to anxiety or mood-related disorders [14]. The youth's emotional experience throughout the admission relies heavily on the grounds for, and the acceptance of, their admission; a traumatic experience poses a future deterrent to voluntary help-seeking [2][15].

With the increase in youth psychiatric hospitalizations across Canada, we expect traumatic care experiences to correspond to this influx. However, research does not address this in the Canadian context. There is a need to examine the experiences of those admitted to psychiatric units to recognize traumatic care experiences and provide recommendations for patient care. To this end, we examined the literature for experiences psychiatry patients perceived as traumatic and explored the positive impacts of TIC on relationships and health outcomes.

\section{Background}

The theoretical framework guiding our understanding of traumatic care and traumainformed care in this integrative review is Swanson's theory of caring [11]. While this theory is traditionally applied to other domains of nursing care such as Neonatal Intensive Care and Labour and Delivery, the theory can be applied to many facets of healthcare including psychiatric care [11]. Swanson's theory consists of five processes knowing, being with, doing for, enabling, and maintaining belief. Knowing is to be unbiased and to focus on gaining an understanding of the meaning of an event to the patient [12]. Being with is being emotionally available, easily accessible, and open to another's reality [12]. This assures patients that their life circumstances are appreciated and recognized [13]. Doing for "entails doing for the other what she or he would do for the self if it were possible" (p. 977) [12], protecting the patient from further harm (i.e., untreated trauma), and respecting human dignity through 
confidentiality and acceptance [13]. Enabling is supporting the patient through unfamiliar events or transitions and the teaching and promotion of self-care techniques [12]. The process of enabling, Swanson [13] explains, has caused many negative connotations, especially when applied to psychiatry settings as the term enabling is associated with the provider maintaining an unhealthy way of being. Contrary to this, Swanson [13] asserts that the goal of nurse caring is to enable clients to achieve well-being. Finally, maintaining belief "is sustaining faith in the other's capacity to get through an event or transition" (p. 977) [12].

Swanson's theory of caring can help inform the approach PCPs take in interacting with patients admitted to psychiatry units who may experience the admission as traumatic. As previously pointed out, experiencing a traumatic event can harm a person's sense of safety, sense of self, and ability to regulate emotions within social relationships. The same event may be more traumatic for some people than others because events are individually interpreted. Swanson's processes of knowing, being with, doing for, enabling, and maintaining belief may assist PCPs to understand the patient's perspective. Further, Swanson's caring processes roughly correspond to trauma-informed care (TIC), an approach to identifying traumatic experiences while minimizing the risk of traumatizing the patient [5]. Six principles constitute TIC: "providing a safe environment for patients, ensuring trustworthiness and transparency, providing patients with peer support, collaboration, and mutuality, empowering the patient by giving him or her a voice and choices, and sensitivity to cultural, historical, and gender issues" [4].

There is an overlap between the principles of TIC and Swanson's caring processes: Both strive to guide safe, collaborative care. Although Swanson [13] focuses on the establishment of the patient-provider relationship, Swanson's theory does not specifically promote patient empowerment. In contrast, TIC promotes patient empowerment by giving the patient a voice and choices. In searching CINAHL and PsychInfo databases, we could locate no published associations between Swanson's theory of caring and trauma-informed care. Despite this, we deem Swanson's theory useful when applied to inpatient psychiatry units and primary care because the theory informs nursing care that will help patients feel connected, accepted, and understood by PCPs. Applying Swanson's caring theory to practice in conjunction with TIC, PCPs will have the ability to holistically fulfill the needs of patients across the age continuum who are suffering from traumatic experiences. The combined Swanson and TIC approach contains elements of collaborative care, provider acceptance, patient acknowledgment, safety, and understanding. Additionally, Swanson's caring process of maintaining belief instills patients with the hope that they can overcome and heal from their experiences.

\section{The integrative review}

We explored the following questions:

1. What key themes of traumatic care are expressed in youth psychiatry unit admissions?

2. How can PCPs assess if youth being discharged from psychiatry units need support recovering from their admission?

3. Should Primary Care Nurse Practitioners incorporate TIC and trauma screening into their practice with youth?

\subsection{Design}

We used Whittemore and Knafl's [16] method which allowed for the broad inclusion of mixed-method, quantitative, and qualitative findings. The Whittemore and Knafl method includes five stages of review: problem identification, literature search, data evaluation, data 
analysis, and presentation. In the problem identification stage, the problem and target population are identified. The results of completing the problem identification stage are shown in the background section. The literature search stage uses well-defined literature searches and encompasses all relevant literature in the review; in addition, we manually searched the references to strengthen the literature search. Data evaluation involves the assessment of the authenticity, methodological quality, informational value, and representativeness of available primary sources. We evaluated the data using the John Hopkins Evidence-Based Practice Model (JHNEBPRS) which required critical appraisal of the research to judge its trustworthiness, value, and relevance [17]. We completed data analysis by constant comparison of similarities and differences among studies, clustering themes, and synthesizing information.

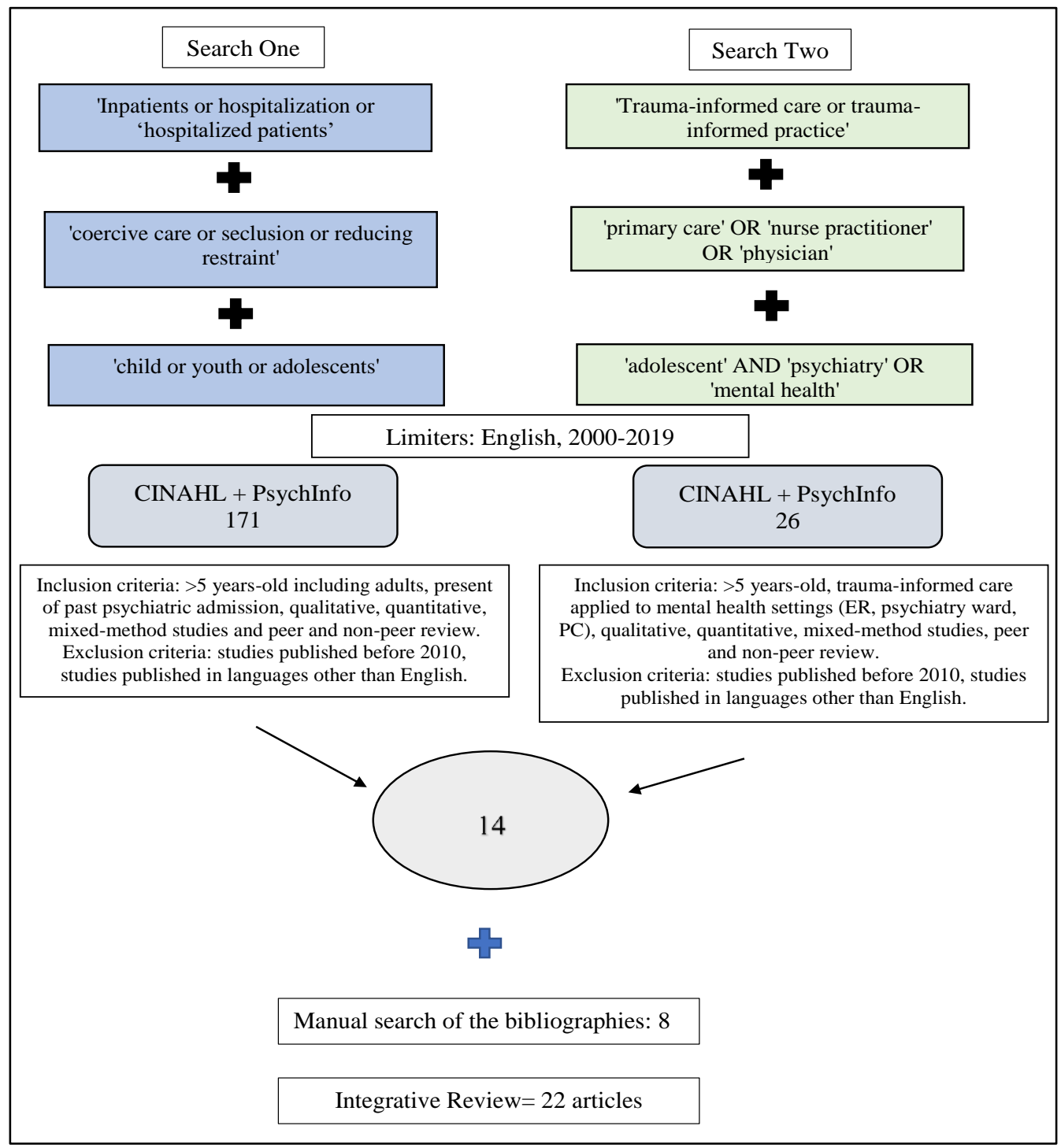

Figure 1. Flow charts of the first and second literature searches using a combination of an electronic and manual search $*$ Note: $\mathrm{ER}=$ emergency room, $\mathrm{PC}=$ primary care 


\subsection{Search methods}

Two separate electronic literature searches were conducted using CINAHL and PsychInfo databases. Search one examined inpatient psychiatry patients and search two examined all caring areas in which TIC is applied [Figure 1]. The first search combining both CINAHL and PsychInfo contained the search terms (inpatients or hospitalization or 'hospitalized patients') AND (coercive care or seclusion or reducing restraint) AND (child or youth or adolescents). The second search used the terms (trauma-informed care or trauma-informed practice) AND ("primary care" OR "nurse practitioner" OR "physician,") AND ("adolescent" AND "psychiatry" OR "mental health"). Both searches applied the following limiters: English and published between the years 2000-2019.

\subsection{Search outcomes}

A total of 22 articles were retained from the electronic and manual searches with duplicates automatically removed. The characteristics of the retained studies (traumatic care, traumaticinformed care) are shown in [Table 1].

Table 1. Summary of traumatic and trauma-informed care articles included in the integrative review.

\begin{tabular}{|c|c|c|c|c|}
\hline \multicolumn{5}{|c|}{ Traumatic care } \\
\hline $\begin{array}{c}\text { Authors, (Date), } \\
\text { Continent }\end{array}$ & Design & Sample Setting & Results & $\begin{array}{l}\text { Quality of } \\
\text { Evidence }\end{array}$ \\
\hline $\begin{array}{l}\text { Bryson et al. } \\
\text { (2017), } \\
\text { North America/ } \\
\quad \text { Europe }\end{array}$ & $\begin{array}{l}\text { A realistic } \\
\text { systemic } \\
\text { review of } 13 \\
\text { articles }\end{array}$ & $\begin{array}{c}9 \text { quantitative, and } \\
4 \text { qualitative } \\
\text { studies }\end{array}$ & $\begin{array}{c}\text { - Factors required to implement TIC are senior } \\
\text { leadership commitment, staff support, } \\
\text { amplifying the voices of patients and families, } \\
\text { the policy that reflects TIC, and data to motivate } \\
\text { change } \\
\text { - Broader therapeutic models may assist to } \\
\text { reduce coercive care }\end{array}$ & III- B \\
\hline $\begin{array}{l}\text { Frueh et al. } \\
\text { (2005), } \\
\text { North America }\end{array}$ & $\begin{array}{l}\text { Cross- } \\
\text { sectional } \\
\text { study }\end{array}$ & $\begin{array}{l}142 \text { randomly } \\
\text { selected adult } \\
\text { psychiatry } \\
\text { patients }\end{array}$ & 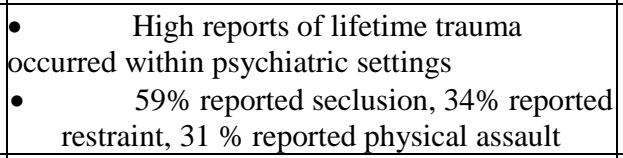 & I- A \\
\hline $\begin{array}{l}\text { Gill, Butler, } \\
\text { Pistrang (2015), } \\
\text { Europe }\end{array}$ & $\begin{array}{c}\text { Qualitative } \\
\text { study }\end{array}$ & $\begin{array}{l}12 \text { adolescent } \\
\text { inpatients aged } \\
13-18\end{array}$ & 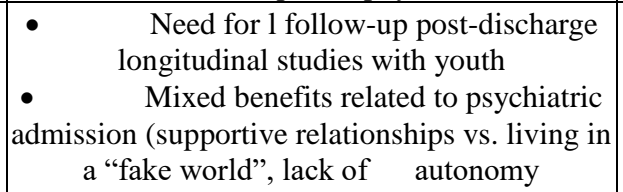 & III- B \\
\hline $\begin{array}{l}\text { Muir-Cochrane, } \\
\text { Oster, Gerace } \\
\text { (2014), } \\
\text { Australia }\end{array}$ & $\begin{array}{l}\text { Quantitative- } \\
\text { retrospective } \\
\text { study }\end{array}$ & $\begin{array}{l}\text { 12-month audit in } \\
\text { one child and } \\
\text { adolescent acute } \\
\text { inpatient mental } \\
\text { health unit }\end{array}$ & \begin{tabular}{|c|} 
Seclusion was the most common \\
restrictive measure recorded \\
Reasons for restrictive measures were \\
harm to self, harm to others, and destruction of \\
property \\
- $\quad$ Important to identify triggers
\end{tabular} & III- B \\
\hline $\begin{array}{l}\text { Muller et al. } \\
\text { (2002), } \\
\text { Europe }\end{array}$ & Quantitative & $\begin{array}{l}135 \text { participants } \\
\text { were investigated } \\
\text { anonymously at } \\
\text { admission and on } \\
\text { discharge over 6- } \\
\text { months }\end{array}$ & $\begin{array}{l}\text { The closed psychiatry ward had lower } \\
\text { satisfaction rates } \\
\text { - } \quad \text { Low satisfaction related to decreased } \\
\text { visiting opportunities, the doctor, the frequency } \\
\text { of psychotherapeutic interventions } \\
\text { Satisfaction is recommended as an } \\
\text { essential measurement beneficial to identifying } \\
\text { improvements in psychiatric inpatient services }\end{array}$ & I- A \\
\hline $\begin{array}{l}\text { Muskett (2013), } \\
\text { North America, }\end{array}$ & Review & $\begin{array}{l}3 \text { retrospective } \\
\text { studies, } 1 \text { RCT, } 6\end{array}$ & $\begin{array}{c}\text { - Universal trauma precautions } \\
\text { - The use of seclusion and restraint is }\end{array}$ & $\mathrm{V}-\mathrm{B}$ \\
\hline
\end{tabular}




\begin{tabular}{|c|c|c|c|c|}
\hline $\begin{array}{c}\text { Europe, and } \\
\text { Australia }\end{array}$ & & \begin{tabular}{|c|} 
qualitative, 1 \\
quantitative, 1 \\
systematic review, \\
1 mixed-methods \\
study
\end{tabular} & \begin{tabular}{|c|} 
retraumatizing \\
Trauma stems from ward rules, ward \\
rounds, search procedures, locked doors, mixed- \\
sex patients, and the use of seclusion and \\
restraint and causes patients to feel emotionally \\
unsafe and disempowered
\end{tabular} & \\
\hline $\begin{array}{c}\text { Nyttingnes et al. } \\
\text { (2016), } \\
\text { (Europe) }\end{array}$ & $\begin{array}{l}\text { Qualitative } \\
\text { research }\end{array}$ & $\begin{array}{l}100 \text { people - } 35 \\
\text { patients/ex- } \\
\text { patients, } 20 \\
\text { mental health } \\
\text { professionals, } 10 \\
\text { carers, 15 } \\
\text { researchers, } \\
\text { lawyers, } \\
\text { journalists or } \\
\text { students, and } 20 \\
\text { unknown } \\
\text { background }\end{array}$ & $\begin{array}{l}\text { - Coercive care is described as humiliation } \\
\text { and Nazism } \\
\text { - Involuntary medication harmed rather than } \\
\text { helped } \\
\text { - Complaints dismissed as lack of insight } \\
\text { - Being 'defined' as the medical model }\end{array}$ & III- B \\
\hline $\begin{array}{l}\text { Pollitt \& } \\
\text { O'Connor } \\
\text { (2007), } \\
\text { Australia }\end{array}$ & Qualitative & $\begin{array}{l}50 \text { former, youth } \\
\text { psychiatry } \\
\text { patients from } \\
\text { three Melbourne } \\
\text { hospitals }\end{array}$ & $\begin{array}{l}\text { - } 34 \% \text { of participants felt frightened, } \\
\text { unsafe, powerless, and undermined at some } \\
\text { point during their hospital stay } \\
24 \% \text { of cases described their } \\
\text { - } \quad \text { experience as 'traumatic' } \\
\text { None met the criteria for PTSD }\end{array}$ & III- B \\
\hline $\begin{array}{l}\text { Pollitt \& } \\
\text { O’Connor } \\
\text { (2008), } \\
\text { Australia }\end{array}$ & Qualitative & $\begin{array}{l}50 \text { former, adult } \\
\text { psychiatry } \\
\text { patients from } 3 \\
\text { Melbourne } \\
\text { hospitals were } \\
\text { interviewed } 15 \\
\text { weeks after } \\
\text { discharge } \\
\end{array}$ & $\begin{array}{l}\text { - } 46 \% \text { had a favorable view of their hospital } \\
\text { admission related to the ward environment, } \\
\text { feelings of recovery } \\
\text { - } 34 \% \text { had some reservations and } 20 \% \text { had a } \\
\text { poor overall view }\end{array}$ & III- B \\
\hline $\begin{array}{c}\text { Raboch et al. } \\
\text { (2010), } \\
\text { Europe }\end{array}$ & Quantitative & $\begin{array}{c}2,030 \text { involuntary } \\
\text { admitted, adult } \\
\text { psychiatry } \\
\text { patients }\end{array}$ & $\begin{array}{c}\text { - } 38 \% \text { of patients experienced coercive } \\
\text { measures } \\
\text { - The most frequent measure used was } \\
\text { forced medications with patient aggression the } \\
\text { most reported reason } \\
\text { - } 60 \% \text { of countries reported using seclusions }\end{array}$ & I- A \\
\hline $\begin{array}{c}\text { Reavey et al. } \\
\text { (2017), } \\
\text { Europe }\end{array}$ & Qualitative & \begin{tabular}{|}
20 youth \\
participants were \\
recruited from (a) \\
a supported \\
discharge group \\
and (b) a \\
treatment-as-usual \\
group
\end{tabular} & $\begin{array}{l}\text { - Advantages to an admission: containment, } \\
\text { safety, supportive relationships } \\
\text { - Disadvantages to an admission: lack of } \\
\text { autonomy, artificial landscapes, inconsistent } \\
\text { staff } \\
\text { - The psychiatry unit was compared to a } \\
\text { 'zoo' or 'holiday camp' }\end{array}$ & III- B \\
\hline $\begin{array}{l}\text { Salamone-Violi, } \\
\text { Chur-Hansen, } \\
\text { Winefield } \\
\text { (2015), } \\
\text { Australia }\end{array}$ & Qualitative & $\begin{array}{l}11 \text { youth } \\
\text { psychiatric } \\
\text { inpatients }\end{array}$ & 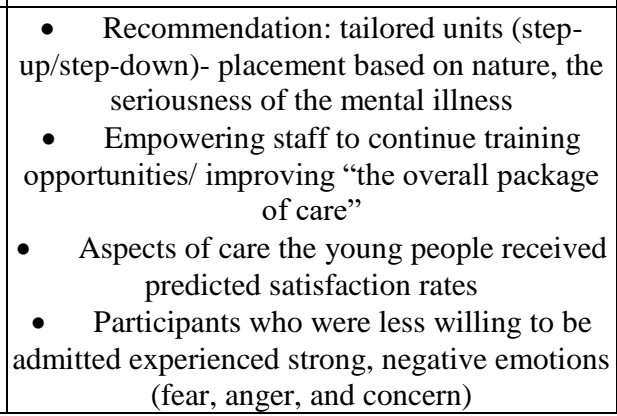 & III- B \\
\hline
\end{tabular}




\begin{tabular}{|c|c|c|c|c|}
\hline \multicolumn{5}{|c|}{ Trauma-informed care } \\
\hline $\begin{array}{c}\text { Authors (Date), } \\
\text { Continent }\end{array}$ & Design & Sample Setting & Results & $\begin{array}{l}\text { Quality of } \\
\text { Evidence }\end{array}$ \\
\hline $\begin{array}{l}\text { Brown, King \& } \\
\text { Wissow (2017), } \\
\text { North America }\end{array}$ & Narrative review & $\begin{array}{l}3 \text { systematic } \\
\text { reviews }\end{array}$ & $\begin{array}{c}\bullet \text { Trusting, personal } \\
\text { relationships, patient-provider } \\
\text { relationships, and collaboration of } \\
\text { providers result in TIC } \\
\text { - } \quad \text { COMPASS Primary Health } \\
\text { and Behavioral Health Questionnaire } \\
\text { • } \quad \text { Integrated care } \\
\end{array}$ & V-B \\
\hline $\begin{array}{l}\text { Bruce et al. } \\
\quad(2018) \\
\text { North America }\end{array}$ & $\begin{array}{l}\text { Cross-sectional } \\
\text { study }\end{array}$ & $\begin{array}{r}147 \text { participants } \\
\text { (nurses, therapists, } \\
\text { and physicians) }\end{array}$ & $\begin{array}{c}\text { - Self-rated competence was the most } \\
\text { consistent predictor of providers' use } \\
\text { - } 19 \% \text { rated themselves as less than } \\
\text { "somewhat competent" } \\
\text { - General provider knowledge and } \\
\text { favorable views toward incorporating } \\
\text { TIC } \\
\text { - Training needed } \\
\text {-Barriers: time constraints, the need for } \\
\text { training, confusing information and } \\
\text { evidence on trauma-informed practices, } \\
\text { and worry about further upsetting or } \\
\text { retraumatizing patients }\end{array}$ & II- A \\
\hline $\begin{array}{l}\text { Esden (2018), } \\
\text { North America }\end{array}$ & Case Study & \begin{tabular}{|c|}
$46-$ year-old, \\
homeless man \\
with a history of \\
childhood trauma, \\
depression, and \\
hospitalization for \\
suicides \\
\end{tabular} & $\begin{array}{l}\text { - ACEs increase the risk of future } \\
\text { unfavorable health outcomes } \\
\text { - PCNPs can help to reduce the } \\
\text { impact of ACEs by identifying these } \\
\text { experiences and implementing TIC } \\
\text { strategies }\end{array}$ & V-B \\
\hline $\begin{array}{l}\text { Green et al. } \\
\quad(2016), \\
\text { North America }\end{array}$ & $\begin{array}{l}\text { Randomized } \\
\text { pilot study }\end{array}$ & $\begin{array}{l}30 \text { PCPs and } 400 \\
\text { of their patients }\end{array}$ & $\begin{array}{c}\text { - Patients rated PCPs higher on a } \\
\text { partnership scale after TIC training } \\
\text { - Lacking provider awareness and } \\
\text { knowledge risks that a trauma exposure } \\
\text { will go undetected, negatively affecting } \\
\text { the patient-provider relationship and } \\
\text { patient engagement in healthcare }\end{array}$ & I- A \\
\hline $\begin{array}{l}\text { Hall et al. } \\
\text { (2016), } \\
\text { Australia }\end{array}$ & $\begin{array}{l}\text { Mixed-method } \\
\text { pilot study }\end{array}$ & $\begin{array}{c}34 \text { ED nurses } \\
\text { participated in TIC } \\
\text { education; 14 ED } \\
\text { nurses participated } \\
\text { in focus groups }\end{array}$ & $\begin{array}{l}\text { TIC education improved their } \\
\text { understanding of TIC, and improved } \\
\text { nurses' confidence in their ability to ask } \\
\text { about, respond to, and understand } \\
\text { trauma and trauma history } \\
\text { Some noted attitudinal shifts } \\
\text { with TIC education }\end{array}$ & II- B \\
\hline $\begin{array}{l}\text { Kassam-Adams } \\
\text { et al. (2015), }\end{array}$ & Quantitative & $\begin{array}{l}232 \text { pediatric } \\
\text { trauma center } \\
\text { nurses }\end{array}$ & $\begin{array}{c}\text { Participants were } \\
\text { knowledgeable and held favorable } \\
\text { opinions of TIC; considered themselves } \\
\text { to be moderately competent }\end{array}$ & II- A \\
\hline $\begin{array}{l}\text { Koetting (2016), } \\
\text { North America }\end{array}$ & $\begin{array}{c}\text { Professional } \\
\text { opinion }\end{array}$ & - & \begin{tabular}{|c|} 
- Conversations are the start of a \\
cultural shift in the workplace \\
- $\quad$ Increasing TIC awareness is vital \\
patients from a state of trauma to one of \\
healing
\end{tabular} & $\mathrm{V}-\mathrm{A}$ \\
\hline $\begin{array}{l}\text { Purkey, Patel, } \\
\text { and Phillips } \\
\text { (2018), } \\
\text { North America }\end{array}$ & Commentary & - & $\begin{array}{c}\text { - Trauma-informed care is essential } \\
\text { for family medicine } \\
\text { The TIC principles guide } \\
\text { physicians unsure how to approach }\end{array}$ & $\mathrm{V}-\mathrm{A}$ \\
\hline
\end{tabular}




\begin{tabular}{|c|c|c|c|c|}
\hline & & & $\begin{array}{l}\text { ACEs } \\
\text { - } \quad \text { ACEs are central to a person's } \\
\text { health and identity } \\
\text { - } \quad \text { ACEs are a key determinant of } \\
\text { many pathologic conditions treated } \\
\text { daily } \\
\text { - A trauma-informed lens can lead } \\
\text { to patient healing and greater } \\
\text { professional satisfaction }\end{array}$ & \\
\hline $\begin{array}{c}\text { Whitecross, } \\
\text { Seeary \& Lee } \\
\text { (2013), } \\
\text { Australia }\end{array}$ & Quantitative & $\begin{array}{c}31 \text { consenting } \\
\text { psychiatry patients } \\
\text { (20\% of secluded } \\
\text { patients) }\end{array}$ & $\begin{array}{c}\text { - Counseling post-seclusion given } \\
\text { resulted in significantly fewer hours } \\
\text { spent in seclusion but did not reduce } \\
\text { the trauma experiences stemming from } \\
\text { seclusion } \\
\text { - } \quad 47 \% \text { reported trauma symptoms } \\
\text { consistent with 'probably post-traumatic } \\
\text { stress disorder related to a recent } \\
\text { seclusion experience } \\
\text { - Need for TIC models which are } \\
\text { sensitive and responsive to seclusion- } \\
\text { related psychological distress } \\
\text { - Need for repeating assessment, } \\
\text { post-discharge to identify chronic, } \\
\text { ongoing symptoms }\end{array}$ & III- B \\
\hline $\begin{array}{l}\text { Williamson \& } \\
\text { Kautz (2016), } \\
\text { North America }\end{array}$ & Expert Opinion & 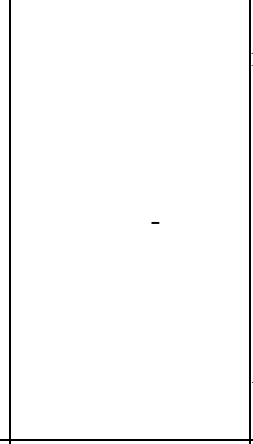 & $\begin{array}{l}\text { TIC promotes rehabilitation, } \\
\text { improves patient outcomes, and reduces } \\
\text { costs } \\
\text { For every } \$ 1 \text { spent on TIC, } \\
\text { - } \$ 5 \text { is saved in lifetime costs } \\
\text { ACEs cause physiological } \\
\text { changes in the brain leading to } \\
\text { antisocial and risky behaviors } \\
\text { TIC is a cultural shift and we } \\
\text { must ask ourselves: "What happened to } \\
\text { this person?" instead of "What is wrong } \\
\text { with this person?" }\end{array}$ & V- B \\
\hline $\begin{array}{l}\text { HCPro (2018), } \\
\text { North America }\end{array}$ & $\begin{array}{c}\text { Case } \\
\text { Management }\end{array}$ & - & $\begin{array}{c}\text {-Application of the three E's: events, } \\
\text { experiences, and effects } \\
\text {-SAMHSA uses to avoid re- } \\
\text { traumatization } \\
\text { - Adherence to the six principles of TIC }\end{array}$ & V- A \\
\hline \multicolumn{5}{|c|}{ 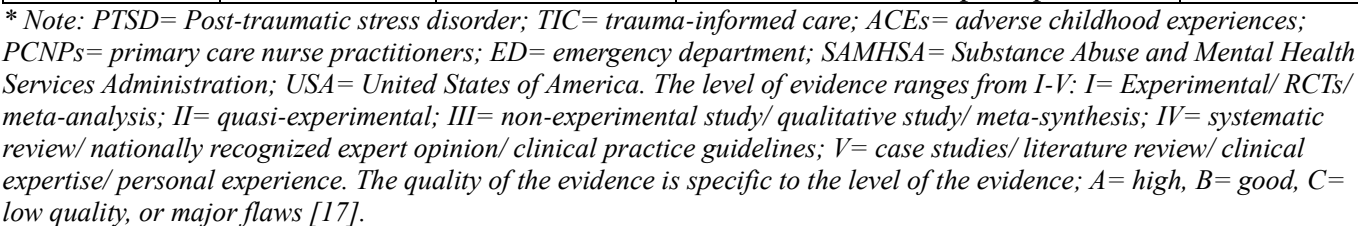 } \\
\hline
\end{tabular}

\subsection{Quality appraisal}

Whittemore and Knafl [16] outline no specific quality criteria for evaluating the quality of integrative reviews. Because there were diverse empirical sources included, we used JHNEBPRS (as previously described in 3.1: Design) to appraise design, adequacy of sample size, instruments utilized, and data analyses. This scale ranks the evidence levels and quality ratings for both quantitative and qualitative studies from levels I to $\mathrm{V}$, where level $\mathrm{I}$ is a randomized control trial and V is a case study, review, or opinion [17]. Once a study is classified by evidence level, it is appraised for quality using the correlated quality criteria 
respective to the evidence level. Table 1 outlines the evidence level and quality ratings we assigned to each of the 22 retained articles. We attained an average quality grade of B (good) and evidence levels ranging from I to V. These results are consistent, transparent, and include scientific evidence.

\subsection{Synthesis}

We compared patterns in the data to build a logical chain of evidence that formed the synthesis of information. We classified and summarized data into two groups: traumatic care and trauma-informed care. Despite the inclusion of diverse data in this integrative review, the reported study findings are consistent with our conclusions synthesized into themes (presented below).

\section{Results}

The first and third guiding research questions: "What are the key themes of traumatic care that exist in youth psychiatry units?" and "What are the key recommendations for primary care nurse practitioners to ensure proper trauma screening is performed and a traumainformed care approach practiced?" were answered using a total of 6 qualitative [2][18][19][20][21][22], 8 quantitative [5][23][24][25][26][27][28][29], 3 professional opinions and/or commentary [6][9][30], 3 reviews [1][31][32], and 2 case studies [4][33]. The key themes are coercive care, seclusions, and loss of control [18][19][21][24][26][28][29], safety [21][22][27][32], and PTSD after discharge [18][29]. The themes of provider knowledge, application of TIC, and the need for recommendations to implement TIC into practice are also present [1][5][6][23][25][30][31][32][33]. The third research question is addressed below in 4.4: Primary care nurse practitioner recommendations.

The second guiding research question: "How can we assess if youth being discharged from psychiatry units need support recovering from their admission?" was unable to be answered due to a gap in the literature. The untreated, negative effects of psychiatry admission for youth patients have yet to be studied in depth. Gill et al. [18] reported the experiences of 12 adolescent inpatients preparing to transition into the community but the data were extracted from within the hospital setting instead of from the transition to the community perspective. Nearly half of Whitecross et al.'s [29] adult inpatient psychiatry participants reported PTSD symptoms during their admission with the traumatic care they experienced; however, psychological readiness for counseling and measurement of traumatic stress were limitations noted due to both being in place immediately after seclusion or traumatic event. This gap in the literature highlights the need for future studies to examine the well-being of youth psychiatry patients after discharge.

\subsection{Traumatic care}

As previously noted, youth psychiatry admissions are on the rise in Canada [14]. Younger psychiatric patients are experiencing significant trauma as a result of their hospitalizations [21]. The primary source of trauma experienced by psychiatric inpatients occurs during admission or as a result of security and unit policies. Being admitted to locked units, having personal belongings checked to ensure they contain nothing with which patients could use to harm themselves (e.g., strings on pants or hoodies, sharp objects, necklaces), being restricted to certain times of the day to have visitors and make telephone contacts to an approvedcontact list, and having no access to social media while on the unit contributes to the trauma. 
Such "routine clinical procedures on inpatient units may, because of the loss of control, represent a highly distressing experience for patients" (p. 1124) [24]. Many inpatients have compared a psychiatry unit admission to being institutionalized [22].

\subsubsection{Coercive care and loss of control}

The word 'coercive' is used to describe care that is rather contradictory and far from therapeutic. In the literature examined, coercive care is linked with strong terms such as humiliation and Nazism [19]. Moreover, coercive care encapsulates negative aspects such as seclusion, restraints, threats, name-calling, and violence [18][19][20][28]. The forms of coercion directly related to traumatic care, such as seclusions and restraints, result from the regulations required to maintain a safe unit. These forms of coercion have been deemed necessary in situations where the patient was at risk of harm to self or others [26]. Though the degree of coercion in Canadian psychiatry wards was not reported, 30-50\% of psychiatry patients admitted involuntarily to psychiatry wards in Europe report having undergone coercive care during their admission [28].

Loss of control is tied to coercive care and is applied to patients feeling a lack of control over various facets of their life, for example, not being in control of what they observe. Common areas in psychiatry units expose patients to other patients' disruptive behaviors, "disturbed patients as a living hell," "nightmare" situations, and "bedlam" (p. 633) [21]. Forced medications are perceived by many patients as unhelpful, causing more harm, and in cases of crisis, furthering their loss of control to make autonomous decisions [22][24][26].

\subsubsection{Safety}

Perceiving the inpatient environment as not safe and supportive can cause trauma [32]. Safety can easily be stripped away from a patient when there is fear of being injured by either staff or fellow patients. Despite safety measures in place in psychiatry wards to minimize the risk of harm to patients, feelings of safety are compromised when exposed to another's disruptive behavior [20]. Experiencing intrusion, lacking privacy, and feeling lonely, disgusted, and embarrassed surface as patient-reported themes in a study of 50 patients in Melbourne, Australia [20].

\subsubsection{PTSD after discharge}

To date, the experiences of psychiatry patients after discharge have focused on adult patients. A gap in the literature exists concerning the experiences of youth psychiatry patients after discharge from the hospital. Despite limited evidence, over half of the 31 patients in Whitecross et al. [29], the study reported symptoms consistent with PTSD. Pollitt and Conner [20] confirm that psychiatry admissions could be deemed 'traumatic' but are unable to support that psychiatric inpatient experiences lead to PTSD.

Traumatic care experiences can pose deterrents to care. Patients who report having had a traumatic experience during their hospital admission are at risk for not seeking healthcare services when appropriate and for falling through the cracks of healthcare.

Psychiatric care frightened the wits out of me, and if I encounter another crisis, it wouldn't even occur to me to seek psychiatric help again. For a long time, I didn't even dare to visit the GP for physical things, out of fear it could lead to another sudden and incomprehensible admission [19] ( p. 150). 


\subsection{Trauma-informed care}

The ethical principle of nonmaleficence (not causing harm) is the major driver of TIC [34]. The Substance Abuse and Mental Health Services Administration (SAMHSA) explain that many patients seeking healthcare treatment have histories of trauma but do not recognize the effects trauma can have on their lives, arguing that patients either do not draw connections or they avoid the topic.

Likewise, treatment providers may not ask questions that elicit a client's history of trauma, may feel unprepared to address trauma-related issues proactively, or may struggle to address traumatic stress within the constraints of their treatment program, the program's clinical orientation, or the agency's directives (p. 3) [34].

The psychological and biological effects of trauma have the potential to mimic symptoms of other diagnoses. Without recognizing traumatic experiences and ruling out trauma-related causes of a patient's symptoms, many diagnoses cannot be concrete. PCPs often fail to consider "how external forces shape what hides inside the body" (p. 170) [9]. An analogy was used to further explore this: "Imagine 3 patients, each with a limp. One has a splinter in his foot, the second has sciatica, and the third had a knee replacement 6 weeks ago" [9]. There are three possible causes of the same limp; but when ineptly exploring the cause, conclusions can be drawn prematurely and be incorrect. The same is true for trauma; if trauma exposures are not explored as potentially causing patient symptoms, medications, and unnecessary treatment may be given while the underlying cause is ignored. SAMHSA [34] explains that many trauma survivors are either misdiagnosed or underdiagnosed potentially resulting from "the fact that general instruments to evaluate mental disorders are not sufficiently sensitive to identify posttraumatic symptoms and can misclassify them as other disorders, including personality disorders or psychoses" (p. 102).

\subsection{Primary care providers' comfort and application of TIC}

Traumatic care from a psychiatry admission is a result of inadvertent causes secondary to admission, security, and unit policies [2][19][21][22][28][29]. Experiencing a traumatic event causes neurophysiological changes which can predispose patients to partake in risky behaviors and increases the likelihood of poor coping, smoking, drug use, alcohol abuse, poor diet, and relationship problems [6][30]. These risky behavior predispositions are major contributors to many chronic diseases; therefore, PCPs may assist in reducing adverse health outcomes when TIC is practiced.

PCPs report low competence concerning the knowledge of and applicability of TIC [23][25]. One study found that over half of the participating nurses had never heard of TIC and were unsure if they were practicing it [5]. As well, providers reported being uncomfortable when dealing with patients who have experienced trauma and PTSD. When TIC training was given to PCPs, patient relationships were shown to improve [5]. Patients ranked the partnerships with their provider higher post-PCP training, further supporting the need for primary care-based continuing education training [5].

As noted in Table 1 (under Traumatic-informed care), 19\% of participants report "less than somewhat competent" at applying TIC to practice [23]. One review of the literature [33] noted that $40 \%$ of physicians in primary care reported having no formal training in TIC and only $4 \%$ of 600 pediatricians completed proper trauma screening. It is evident that provider comfort levels are inconsistent and require improvement. 


\subsection{Primary Care Nurse Practitioner (PCNP) recommendations}

Based on the synthesis of the literature, we recommend the following:

- PCNPs identify, through self-reflection, their knowledge needs to practice TIC safely and completely

- PCNPs form therapeutic relationships with other care providers

- PCNPs understand the etiology of trauma and recognize psychiatric traumatic care

- PCNPs understand the key elements of TIC (prevalence, effects, knowledge) covered by SAMHSA [34]

- PCNPs maintain an empathetic approach

- PCNPs broaden knowledge through online toolboxes and programs

- Universities incorporate TIC training into their curriculums for all healthcare providers

- PCNPs advocate for curriculum changes at the university level through participation in stakeholders' meetings and guest lectures, and through precepting students in a TIC environment

- Universal trauma screening be performed at hospital admission and after discharge (especially after a discharge from a psychiatry admission)

To incorporate TIC into practice, three key elements must be met: (1) the provider can realize the prevalence of trauma; (2) the provider recognizes how trauma affects all individuals involved in caring for the patient; and (3) the provider responds by putting this knowledge into practice [34]. The caring environment and all persons working in it (e.g., PCNPs, other providers, and receptionists) must interact using a TIC approach. PCNPs practicing in community health centers must use their leadership skills to teach their colleagues the basics and importance of TIC.

Maintaining an empathetic approach conveys to patients the PCNP's deep understanding of the patient's illness and the benefits versus the negative effects of the psychiatry unit admission. Sustaining open communication and respect for the patient are vital components of a trauma-informed approach [5][23][31]. Successful TIC implementation strategies include incorporating universal screening for a history of trauma at the time the patient is admitted to psychiatry, transforming impersonal spaces in hospitals and primary care offices into more homely and welcoming environments, recognizing the importance of therapeutic relationships and 'talking' therapies, and understanding the critical importance of emotionally supportive care [32]. Adapting universal screening upon admission to the care model in psychiatry is recommended to minimize missed screening of patients' trauma histories; therefore, it is recommended that universal screenings be implemented into primary care practice to identify all patients suffering from trauma. By applying universal screening, PCNPs will reduce the risk of not identifying patients who are experiencing the negative effects of trauma. In addition to screening, close management, support, and follow-up are required.

PCNPs must be capable of forming therapeutic relationships, problem-solving, and resisting simple solutions [31]. It is suggested that integrated care models, strong leadership skills, and a drive for self-learning will assist PCNPs to overcome barriers of time constraints and inadequate training [23][31]. Complex patient problems can be addressed through flexibility, mutually supportive teamwork, and collaboration among healthcare professionals who are easily accessible [31][34].

The knowledge that trauma exposure predicts mental disorders and poor health outcomes for patients has not yet influenced medical or nursing curriculum, as supported by reports that minimal TIC training is given to nurses or physicians while in training [5]. It follows that healthcare educational curricula must incorporate trauma-informed care. PCNPs could 
advocate for changes in the curricula of educational institutions to incorporate TIC into training through partaking in stakeholders' meetings and guest lectures. As well, PCNPs acting as preceptors to students should lead by example, fostering their students' learning in a TIC environment. TIC and trauma training may seem like insignificant pieces of the larger healthcare puzzle, but patients are at risk of being improperly diagnosed and mismanaged when traumatic experiences are overlooked.

\subsection{Resources for TIC training}

Until the academic systems take action to incorporate TIC into their programs, we strongly recommend that PCNPs self-reflect to identify their learning needs. PCNPs can self-educate through programs like the Crisis Prevention Institute (https://www.crisisprevention.com) and the 'Trauma-Informed Care' and Healthcare toolbox (https://www.chop.edu/centersprograms/ center-pediatric-traumatic-stress). The online toolbox for assisting children and families to cope with illness and injury [5] provides screening guidance using the acronym DEF which stands for D: reducing distress (asking about fears and worries), E: providing emotional support (who and what does the patient need now), and F: remembering to gauge family stressors and resources [35]. DEF is useful for PCNPs as it is the next step in providing basic care following $\mathrm{ABC}$ (airway, breathing, circulation) and attending to the patient's psychosocial needs [35]. With training, PCNPs can use screening tools available for post-traumatic stress disorder symptoms and trauma recommended by SAMHSA that include assessing trauma-related symptoms, depressive symptoms, sleep disturbances, and substance abuse [34].

It is not known how prevalent hospital-related PTSD is due to a gap in the literature; however, the discharge of a patient back into primary care should alert the PCNP to follow up and screen the patient for traumatic care. It is advised that PCNPs ask themselves "what has happened to this person over time?" as opposed to "what is wrong with the person?" when questioning patient behaviors [6][30]. This assists the provider to appreciate the adaptive behaviors that trauma patients have developed and to further shifting this association of trauma away from pathology toward resilience [34]. The embracing of the adaptive component of trauma-related reactions fosters a hopeful, strengths-based stance that can build upon patient qualities of creativity, self-preservation, and determination [34].

\section{Discussion}

The design of this integrative review allowed for the broad inclusion of mixed-methods, quantitative, and qualitative research which is proven to be a beneficial approach to building an evidence-based practice in nursing [16]. Although Whittemore and Knafl suggest appraising the literature only when outliers are surfaced, we used the JHNEBPRS to evaluate the level of evidence of the articles included in the review. Overall, the strength and transferability of findings regarding traumatic care and trauma-informed care were highly relevant and consistent across Australian, European, and American contexts despite cultural differences which can be noted in Table 1. The gap in the literature for studies assessing the well-being of youth psychiatry patients after discharge and for Canadian studies were the major limitations noted. Our findings suggest the need for Canadian research that directly includes youth psychiatry patients as participants to confirm the consistency of the global findings. 


\section{Conclusion}

Traumatic care occurs frequently in youth psychiatry units and results inadvertently from admission, unit, and safety policies such as locked units and reduced access to family and friends. Moreover, the greater proportion of traumatic care stems from coercive care that includes involuntary admission, seclusions, loss of control, and threats to personal safety. Although many patients report the stabilization of their mental illness at discharge, they find themselves later on confronting the traumatic care experiences of the admission.

This integrative review outlines the experiences of youth psychiatry patients from across the globe, stressing the importance of implementing trauma-informed care into all caring settings. We recommend screening for trauma for all psychiatry patients discharged from the hospital. PCPs must be mindful of the potential for their patient to encounter difficulties healing from the negative aspects of otherwise successful psychiatric admission. The findings note the need for further evaluation of discharged youth to gain a more concrete understanding of the effects of traumatic care and the incidence of PTSD diagnoses in youth discharged from a psychiatric admission. Additionally, due to PCPs reporting a lack of TIC training, educational institutions responsible for preparing healthcare providers require curricula inclusion of TIC teachings.

As guided by Swanson's caring theory, PCNPs will maintain an empathetic approach to reaffirm that patients feel their provider's understanding of their illness and the advantages of hospital admission. Maintaining open communication, being respectful, and assisting the patient through the healing process are other vital components of applying Swanson's theory to a trauma-informed care approach. PCNPs will benefit from having a strong knowledge base of the diverse human responses and symptoms of traumatic stress, as well as an ability to assist their patient in navigating the system further for community-based treatment. Advocating for TIC in inpatient and educational settings, broadening the trauma-screening lenses in primary care, partaking in trauma-informed training, and using a trauma-informed approach in practice will help reduce risks associated with untreated trauma symptoms and adverse health outcomes for youth psychiatric patients and patients across the care continuum.

\section{References}

[1] S. Bryson, E. Gauvin, A. Jamieson, M. Rathgeber, L. Faulkner-Gibson, S. Bell, and S. Burke, "What are effective strategies for implementing trauma-informed care in youth inpatient psychiatric and residential treatment settings? A realist systematic review," International Journal of Mental Health Systems, vol.11, no.36, pp.1-16, (2017) DOI:10.1186/s13033-017-0137-3

[2] G. Salamone-Violi, A. Chur-Hansen, and H. Winefield, "I don't want to be here but I feel safe": Referral and admission to a child and adolescent psychiatric inpatient unit: The young person's perspective," International Journal of Mental Health Nursing, vol.24, no.6, pp.569-576, (2015) DOI:10.1111/inm.12163

[3] M. Valenkamp, K. Delaney, and F. Verheij, "Reducing seclusion and restraint during child and adolescent inpatient treatment: Still an underdeveloped area of research," Journal of Child and Adolescent Psychiatric Nursing, vol.27, no.4, pp.169-174, (2014) DOI10.1111/jcap.12084

[4] HCP Pro, "Trauma-informed care: What it is, how to use it," Case Management Monthly, vol.15, no.8, pp.4-5, (2018) Retrieved from https://hcmarketplace.com/case-management-monthly

[5] B. Green, P. Saunders, Power, P. Dass-Brailsford, K. Schelbert, E. Giller, and M. Mete, "Trauma-informed medical care: patient response to a primary care provider communication training," Journal of Loss \& Trauma, vol.21, no.2, pp.147-159, (2016) DOI:10.1080/15325024.2015.1084854 
[6] L. Williamson and D. Kautz, "Trauma-informed care is the best clinical practice in rehabilitation nursing," Rehabilitation Nursing. vol.3, no.2, pp.73-80, (2016) DOI:10.1002/rnj.311

[7] Mood Disorders Society of Canada, "Mental health care system study summary report," Mood Disorders Society of Canada, pp.1-48, Retrieved from https://mdsc.ca/wp-content/uploads/2016/05/MDSC_2015_Mental_Health_Care_Survey_Report.pdf, (2015)

[8] M. J. Müller, R. Schlösser, G. Kapp-Steen, B. Schanz, and O. Benkert, "Patients' satisfaction with psychiatric treatment: Comparison between an open and a closed ward,” Psychiatric Quarterly, vol.73, no.2, pp.93-107, (2002) DOI:10.1023/A:1015099526445

[9] E. Purkey, R. Patel, and S. Phillips, "Trauma-informed care- Better care for everyone," Canadian Family Physician, vol.6, no.3, pp.170-172, (2018) Retrieved from: http://www.cfp.ca/

[10] E. Hopper, E. Bassuk, and J. Olivet, "Shelter from the storm: Trauma-informed care in homelessness services settings," The Open Health Services and Policy Journal, vol.3, pp.80-100, Retrieved from https://benthamopen.com/contents/pdf/TOHSPJ/TOHSPJ-3-80.pdf, (2010)

[11] K. Swanson, "Caring made visible," Interview by Pat Jakobsen. Retrieved from: http://nursing.unc.edu/files/2012/11/ccm3_032551.pdf

[12] M. Kalfoss and J. Owe, "Empirical verification of Swanson's caring processes found in nursing actions: Systematic Review," Open Journal of Nursing, vol.5, no.11, pp.976-986, (2015) DOI:10.4236/ojn.2015.511104

[13] K. Swanson, "Nursing as informed caring for the well-being of others," Retrieved from http://nursing.unc.edu/files/2012/11/ccm3_032549.pdf

[14] Canadian Institute for Health Information, "Care for children and youth with mental disorders: Data Tables," Retrieved from https://www.cihi.ca/en/access-data-reports/results/date?f\%5B0\%5D=field_primary_ theme $\% 3 \mathrm{~A} 2052 \& \mathrm{f} \% 5 \mathrm{~B} 1 \% 5 \mathrm{D}=$ field_primary_theme $\% 3 \mathrm{~A} 2065 \& \mathrm{f} \% 5 \mathrm{~B} 2 \% 5 \mathrm{D}=$ field_primary_theme $\% 3 \mathrm{~A} 2055$ $\& \mathrm{f} \% 5 \mathrm{~B} 3 \% 5 \mathrm{D}=$ field_types_of_care\%3A1970\&f\%5B4\%5D=field_types_of_care\%3A2020,(2018)

[15] M. Swartz, J. Swanson, and M. Hannon, "Does fear of coercion keep people away from mental health treatment? Evidence from a survey of persons with schizophrenia and mental health professionals," Journal of Behavioral Sciences and the Law, vol.21, no.4, pp.459-472, (2003) DOI:10.1002/bsl.539

[16] R. Whittemore and K. Knafl, "The integrative review: updated methodology". Journal of Advanced Nursing, vol.52, no.5, pp.546-553, https://doi.org/10.1111/j.1365-2648.2005.03621.x, (2005)

[17] D. Dang and S. Dearholt, "John-Hopkins nursing evidence-based practice: model and guidelines," Retrieved from https://www.hopkinsmedicine.org/evidence-based-practice/ijhn_2017_ebp.html, (2017)

[18] F. Gill, S. Butler, and N. Pistrang, "The experience of adolescent inpatient care and the anticipated transition to the community: Young people's perspectives," Journal of Adolescence, vol.46, pp.57-65, (2016) DOI:10.1016/j.adolescence.2015.10.025

[19] O. Nyttingnes, T. Ruud and J. Rugkåsa, "It's unbelievably humiliating' - Patients' expressions of negative effects of coercion in mental health care," International Journal of Law and Psychiatry, vol.49, no. Part A, pp.147-153, (2016) DOI:10.1016/j.ijlp.2016.08.009

[20] P. Pollitt and D. W. O'Connor, “Are patients with severe depression traumatized by admission to an aged psychiatry ward?" International Psychogeriatrics, vol.19, no.1, pp.115-123, (2007) DOI: 10.1017/S1041610206003516

[21] P. Pollitt, and D. O'Connor, "What was good about admission to an aged psychiatry ward? The subjective experiences of patients with depression," International Psychogeriatrics, vol.20, no.3, pp.628-640, (2008) DOI:10.1017/S104161020700600X

[22] P. Reavey, J. Poole, R. Corrigall, T. Zundel, S. Byford, M. Sarhane, and D. Ougrin, "The ward as emotional ecology: Adolescent experiences of managing mental health and distress in psychiatric inpatient settings," Health \& Place, vol.46, pp.210-218, (2017) DOI: 10.1016/j.healthplace.2017.05.008 
[23] M. Bruce, N. Kassam-Adams, M. Rogers, K. Anderson, K. Sluys, and T. Richmond, "Trauma providers' knowledge, views, and practice of trauma-informed care," Journal of Trauma Nursing, vol.25, no.2, pp.131138, (2018) DOI: 10.1097/JTN.0000000000000356

[24] B. Frueh, R. Knapp, K. Cusack, A. Grubaugh, J. Sauvageot, V. Cousins, E. Yim, C. Robins, J. Monnier, and T. Hiers, "Special section on seclusion and restraint: Patients' reports of traumatic or harmful experiences within the psychiatric setting," Psychiatric Services, vol.56, no.9, pp.1123-1133, Retrieved from https://ps.psychiatryonline.org/, (2005)

[25] A. Hall, B. McKenna, V. Dearie, T. Maguire, R. Charleston, and T. Furness, "Educating emergency department nurses about trauma-informed care for people presenting with a mental health crisis: a pilot study, "BMC Nursing, vol.15, pp.1-8, (2016) DOI:10.1186/s12912-016-0141-y

[26] E. Muir-Cochrane, C. Oster and A. Gerace, "The use of restrictive measures in an acute inpatient child and adolescent mental health Service," Archives of Psychiatric Nursing, vol.28, no.6, pp.389-391, (2014) DOI: 10.1016/j.apnu.2014.08.015

[27] M. J. Müller, R. Schlösser, G. Kapp-Steen, B. Schanz, and O. Benkert, "Patients' satisfaction with psychiatric treatment: Comparison between an open and a closed ward," Psychiatric Quarterly, vol.73, no.2, pp.93-107, (2002) DOI: 10.1023/A:1015099526445

[28] J. Raboch, L. Kalisova, A. Nawka, E. Onchev, G. Karastergiou, L. Magliano, and T. Kallert, "Use of coercive measures during involuntary hospitalization: Findings from ten European countries," Psychiatry Services, vol.61, no.10, pp.1012-1017, Retrieved from psychiatryonline.org, (2010)

[29] F. Whitecross, A. Seary, and S. Lee, "Measuring the impacts of seclusion on psychiatry inpatients and the effectiveness of a pilot single - session post - seclusion counseling intervention," International Journal of Mental Health Nursing, vol.22, no.6, pp.512-521, (2013) DOI:10.1111/inm.12023

[30] C. Koetting, "Trauma-informed care: helping patients with a painful past," Journal of Christian Nursing, vol.33, no.4, pp.206-213, Retrieved from https://shop.lww.com/Journal-of-Christian-Nursing/p/0743-2550, (2016)

[31] J. Brown, M. King, and L. Wissow, "The central role of relationships with trauma-informed integrated care for children and youth," Child Well-Being and Adverse Childhood Experiences in the US, vol.17, no.7, S94S101, (2017) DOI:10.1016/j.acap.2017.01.013

[32] C. Muskett, "Trauma-informed care in inpatient mental health settings: A review of the literature," International Journal of Mental Health Nursing, vol.23, no.1, pp. 51-59, (2014) DOI:10.1111/inm.12012

[33] J. Esden, "Adverse childhood experiences and implementing trauma-informed primary care," Nurse Practitioner, vol.43, no.12, pp.10-21, (2018) DOI: 10.1097/01.NPR.0000547550.48517.e9

[34] Substance Abuse and Mental Health Services Administration, A treatment improvement protocol: Traumainformed care in behavioral health services, Retrieved from https://store.samhsa.gov/system/files/sma144816.pdf, (2014)

[35] Children's Hospital. Center for Pediatric Traumatic Stress, Retrieved from https://www.chop.edu/centersprograms/center-pediatric-traumatic-stress, (2014) 


\section{Authors}

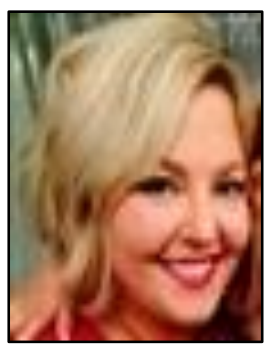

\section{Jane McLaughlin}

is a Primary Care Nurse Practitioner in Miramichi, New Brunswick, Canada.

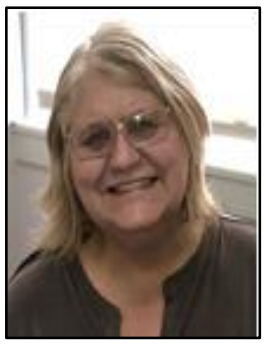

\section{Kathryn Weaver}

is a Professor and Director of Graduate Studies Nursing at the University of New Brunswick, Canada. 
An Integrative Review: Translating the Experiences of Youth Psychiatry Patients to Improve Primary Healthcare Outcomes

This page is empty by intention. 